\title{
Clínica de atenção básica: do discurso teórico à realidade prática
}

\author{
Nelson Rubens Mendes Loretto*, Ileamá Duque Porto Pessoa Silva**, Leila Christiane \\ Lima Carneiro Batista** \\ * Professor Adjunto Doutor, Orientador \\ ** Alunas do $10^{\circ}$ período do curso de graduação da FOP-UPE, \\ Pesquisadoras
}

\section{RESUMO}

Objetivo: Analisar a coerência ideológica de formação ao verificar se a realidade prática do treinamento do estudante do curso de graduação na clínica de atenção básica corresponde ao discurso teórico contido no projeto políticopedagógico do curso. Metodologia: estudo exploratório, descritivo, transversal, quanti-qualitativo realizado com 35 alunos e 9 docentes da Clínica de Atenção Básica I e II de uma Faculdade de Odontologia do estado de Pernambuco. O estudo quantitativo foi utilizou um questionário com dez situações de ensino/aprendizagem respondido mediante uma escala de Likert de 4 opções. O estudo qualitativo utilizou a técnica de análise do conteúdo de Bardin realizada sobre três questões abertas. A estatística descritiva e inferencial utilizou o teste Qui-Quadrado de Pearson e para comparação de médias o teste de Mann Whitney. Resultados: o teste de comparação de médias entre alunos e docentes da CAB I mostrou significância somente nas situações de interdisciplinaridade, multidisciplinaridade e transdisciplinaridade $(\mathrm{p}=0,012)$; seleção de pacientes $(\mathrm{p}=0,045)$; e conhecimento e cobrança de conhecimentos ministrados nas unidades anteriores $(\mathrm{p}=0,001)$. $\mathrm{Na}$ CAB II a associação significativa foi para seleção de pacientes $(\mathrm{p}=0,004)$; conhecimento e cobrança dos conteúdos ministrados nas unidades anteriores $(\mathrm{p}=0,001)$; apoio às atividades para fins diagnósticos $(\mathrm{p}=0,001)$. Conclusões: Não há coerência entre o discurso do PPP da instituição e a realidade prática das CABs I e II; a melhoria na triagem, a interdisciplinaridade e o compromisso e competência docente são as melhorias mais exigidas pelos alunos; e o fortalecimento da interdisciplinaridade e a organização dos prontuários são as mais exigidas pelos docentes.

\section{DESCRITORES}

Educação em odontologia. Atenção primária à saúde. Saúde bucal.
S princípios da Reforma Sanitária consagrados na Lei Orgânica da Saúde de nº 8.080/1990 e na criação do Sistema Único de Saúde apontaram para um novo perfil profissiográfico nas profissões de saúde, aí incluída a Odontologia. Toda formação e atenção antes voltada para a doença, agora se volta para o doente e suas condições sócio-ambientais, refutando a ideologia flexneriana que trazia no seu cerne, como forte elemento de identificação, o biologismo, elemento ideológico determinante na forma de ensinar e de dar assistência à saúde. ${ }^{1}$ Dessa aproximação entre Educação e Saúde resultaram as Diretrizes Curriculares Nacionais (DCN), que têm como ideário básico à flexibilização curricular, com vistas a possibilitar uma sólida formação de acordo com o estágio de desenvolvimento do conhecimento em cada área, permitindo ao graduado enfrentar as rápidas mudanças do conhecimento e seus reflexos no mundo do trabalho. Desde a sua aprovação, os currículos devem ser propostos de modo a contemplar, para cada curso, o perfil acadêmico e profissional, as competências, neles estabelecidos, a partir de referências nacionais e internacionais. ${ }^{2} \mathrm{~A}$ formação pretendida sinaliza para o treinamento do estudante na formação e desenvolvimento de habilidades e competências clínicas em clínicas de atenção hierarquizadas denominadas Clínica de Atenção Básica (CAB), Clínica de Atenção de Média Complexidade (CAMC) e Clínica de Atenção de Alta Complexidade (CAAC) . A ideologia dessas clínicas deve fazer parte do projeto político-pedagógico (PPP) do curso, superando a formação em clínicas estanques, desarticuladas da realidade social e que refletiam ainda o modelo flexneriano biologicista. Dessa forma, ao elaborar seu PPP a instituição pesquisada apresentou seu modelo de formação no qual se inclui a Clínica de Atenção Básica como primeira experiência clínica do aprendiz, situada no $5^{\circ}$ período do curso. ${ }^{3}$ A atenção básica foi definida pela Organização Mundial de Saúde (OMS), em 1978, 
como atenção essencial baseada em tecnologia e métodos práticos, cientificamente comprovados e socialmente aceitáveis, tornados universalmente acessíveis a indivíduos e famílias na comunidade por meios aceitáveis para eles e a um custo que tanto a comunidade como o país possa arcar em cada estágio de seu desenvolvimento, um espírito de autoconfiança e autodeterminação. É parte integral do sistema de saúde do país, do qual é função central, sendo o enfoque principal do desenvolvimento social e econômico global da comunidade. É o primeiro nível de contato dos indivíduos, da família e da comunidade com o sistema nacional de saúde, levando a atenção à saúde o mais próximo possível do local onde as pessoas vivem e trabalham, constituindo o primeiro elemento de um processo de atenção continuada à saúde. ${ }^{4}$ A formação atual em Odontologia obedece a Resolução CNE/CES n ${ }^{\circ}$ 3, de 19 de fevereiro de 2002 da Câmara de Educação Superior do Conselho Nacional de Educação (CNE/CES, 2002) que fixou as Diretrizes Curriculares Nacionais de Odontologia que no seu artigo $5^{\circ}$, ao tratar das competências e habilidades específicas estabeleceu no inciso III que o futuro dentista deve

\footnotetext{
"atuar multiprofissionalmente, interdisciplinarmente e transdisciplinarmente com extrema produtividade na promoção da saúde baseado na convicção científica, de cidadania e de ética."
}

Esse, sem duvida, é o inciso mais importante do ideário da formação, posto que supera a fragmentação do ser, remetendo a compreensão do paciente na sua totalidade ou, na chamada visão holística. Essa parece ser uma das grandes dificuldades das IES na implantação das Diretrizes Curriculares Nacionais de Odontologia (DCNO), posto que ultrapassar o antigo modelo curricular, de natureza conteudista e forte marca de poder pelo exercício das cátedras. Por essa razão, Cordioli (2006) ao pesquisar egresso com até cinco anos de formado sintetizou que

\footnotetext{
os principais achados evidenciam aspectos essenciais que ainda dificultam a concretização do perfil de egresso preconizado pelas Diretrizes Curriculares, especialmente no tocante ao preparo para uma prática generalista da profissão. Salienta-se a falta de articulação da teoria com a prática, uma visão da Odontologia descontextualizada da realidade com conseqüente despreparo para atuação no mercado de trabalho, uma ênfase intra-profissional com pouca integração com as outras áreas da saúde, uma formação inadequada para o trabalho no contexto do SUS,
}

um preparo inadequado para ações ligadas à administração e gerenciamento da própria prática e pouco preparo para o relacionamento com o paciente e com os outros profissionais da própria área.

O currículo é um dos conceitos mais potentes, estrategicamente falando, para analisar como a prática se sustenta e se expressa de uma forma peculiar dentro de um contexto escolar. ${ }^{5}$

A faculdade pesquisada discutiu seu PPP nos anos de 2004 e 2005 e em 2006 chegou à redação do documento final de 126 páginas, no qual transparecia a adequação do ensino de graduação às DCNO. A última reforma curricular dessa instituição tinha sido em 1992. A partir de 2008 os ingressantes no curso passaram a vivenciar o novo currículo disposto no PPP. A discussão que se fez em dois anos trouxe à tona os problemas institucionais mais agudos, a saber:

- carga horária excessiva;

- falta de interdisciplinaridade;

- grade curricular engessada;

- currículo inadequado;

- conteúdos repetitivos;

- aulas magistrais;

- superlotação de clínicas e laboratórios; e

- falta de integração básico profissional.

Uma pergunta se fez necessária: a atual formação clínica orientada pelo discurso teórico do PPP da instituição pesquisada encontra ressonância na primeira experiência clínica do aluno, denominada Clínica de Atenção Básica?

\section{MATERIAIS E MÉTODOS}

Este estudo, de caráter exploratório e descritivo, corte transversal e natureza quali-quantitativa, foi realizado em dois momentos distintos, com uma mesma população, a saber: trinta e cinco alunos matriculados na Clínica de Atenção Básica I (CAB I) do $5^{\circ}$ período (equivalentes aos $100 \%$ do total de alunos matriculados) do curso de graduação de uma faculdade de odontologia do estado de Pernambuco e nove docentes atuantes na referida clínica e repetido com a mesma população no semestre seguinte quando os alunos foram matriculados na Clínica de Atenção Básica II (CAB II) no $6^{\circ}$ período. Foram considerados incluídos na pesquisa todos os alunos regularmente matriculados, sem nenhum regime de dependência do semestre anterior ou que estivesse cursando a CAB I como disciplina isolada, e os docentes em efetivo exercício das atividades docentes nas CAB I e II. Para a 
metodologia quantitativa foi elaborado um questionário dividido em duas partes:

- a primeira para registro de dados sociodemográficos de ambos os grupos.

- para os docentes: gênero, idade,especialidade e titulação e

- para os discentes: gênero e idade.

- A segunda parte do questionário foi composta por dez situações de ensino-aprendizagem elaboradas a partir do PPP da instituição e das DCNO e que podem ser resumidas nas seguintes categorias:

1. valores morais e conduta social;

2. interdisciplinaridade, multidisciplinaridade e transdisciplinaridade;

3. integração com sistema de saúde;

4. nível de resolutividade;

5. uso de metodologias ativas;

6. adequação de necessidades ao nível de formação;

7. exigência e utilização dos pré-requisitos;

8. apoio para construção de diagnóstico;

9. apoio para plano de tratamento; e

10. atuação norteada pelo PPP e DCNO.

Uma escala de Likert foi utilizada com as seguintes sub-escalas:

- (0) nunca,

- (1) algumas vezes,

- (2) muitas vezes e

- (3) sempre.

Para conhecer a média de avaliação em cada uma das questões oferecidas e que retratavam situações de ensino (docentes) e de aprendizagem (alunos) somou-se o valor da resposta de cada aluno e cada docente para cada uma das questões, dividindo-se o total pelo número de sujeitos respondentes. $\mathrm{O}$ valor encontrado foi a média alcançada pela questão em cada grupo pesquisado e esse valor foi interpretado segundo a escala de Likert. As médias de docentes e discentes foram comparadas e para estatística inferencial utilizou-se o teste de Mann-Whitney. Para a metodologia qualitativa foi utilizada a entrevista dirigida, devendo cada pesquisado responder três perguntas (abertas) condutoras, sem nenhuma interferência das pesquisadoras. No primeiro momento pensou-se em gravar as respostas, mas o estudo piloto realizado com 6 alunos e 3 docentes que não fizeram parte da amostra (eram de outro período), revelou, por parte dos alunos, a preocupação com a entrevista gravada, sugerindo que as respostas às perguntas fossem dadas por escrito. Assim foi feito. Todas as respostas forma analisadas segundo a técnica da análise de conteúdo ${ }^{6}$ utilizando-se as estratégias propostas por Minayo, ${ }^{7}$ a qual inclui a pré-análise, a exploração do material ou codificação e o tratamento dos resultados obtidos.

\section{RESULTADOS E DISCUSSÃO}

Do ponto de vista quantitativo a amostra discente revelou-se predominantemente feminina (80\%) seguindo uma tendência natural nos cursos de Odontologia com a presença sempre majoritária das mulheres e a idade média masculina foi de 21,7 anos e feminina de 21,6 anos. Entre os docentes 55,6\% eram homens e 44,4\% mulheres. A titulação apontou 77,8\% de doutores; $11,1 \%$ de especialista e $11,1 \%$ de pós-doutor. As disciplinas com maior número de docentes foram Periodontia e Dentística com 33,3\% dos professores cada uma. Olhando o conjunto das respostas de alunos e professores e levando em consideração as sub-escalas de respostas (nunca, algumas vezes, muitas vezes e sempre) o resultado comparativo entre as duas categorias amostrais foi expresso conforme a Tabela 1.

A diferença entre as médias foi muito elevada na resposta NUNCA pois o valor dos docentes foi 5,96 vezes maior do que o dos alunos quando atribuíram NUNCA a sua situação de ensino. Ou seja, os professores reconhecem que "nunca" realizam ou procedem em uma determinada atuação na sua situação de ensino, mas isso não é percebido pelo aluno na sua situação de aprendizagem. Claro está que aqui estamos falando do conjunto das situações. Para melhor entendermos o problema em cada questão isoladamente, foi construída a Tabela 2 a que compara a média de respostas de alunos e docentes.

A questão 2 trata dos conceitos de interdisciplinaridade, multidisciplinaridade e transdisciplinaridade que modernamente devem fazer parte dos processos pedagógicos de formação, especialmente na área da saúde.

A questão 6 invoca algo que podemos considerar um nó crítico da $\mathrm{CAB}$, qual seja, a seleção de pacien-

Tabela 1 - Distribuição relativa da média de respostas de alunos e docentes segundo a sub-escala.

\begin{tabular}{|l|c|c|c|c|}
\hline Resposta & Nunca & $\begin{array}{c}\text { Algumas } \\
\text { vezes }\end{array}$ & $\begin{array}{c}\text { Muitas } \\
\text { vezes }\end{array}$ & Sempre \\
\hline Alunos & 2,8 & 39,8 & 40,4 & 17,0 \\
\hline Docentes & 16,7 & 23,3 & 32,2 & 27,8 \\
\hline
\end{tabular}


Tabela 2 - Teste de Médias entre alunos e docentes da CAB I.

\begin{tabular}{|c|c|c|c|c|c|}
\hline Questão & Grupo & $\mathbf{N}$ & Média & $\begin{array}{l}\text { Desvio } \\
\text { padrão }\end{array}$ & $\begin{array}{c}\text { Valor de } \\
p^{(1)}\end{array}$ \\
\hline \multirow{2}{*}{ Q1 } & Alunos & 35 & 2,09 & 0,658 & \multirow{2}{*}{0,308} \\
\hline & Docentes & 9 & 2,33 & 0,707 & \\
\hline \multirow{2}{*}{ Q2 } & Alunos & 35 & 1,23 & 0,646 & \multirow{2}{*}{0,012} \\
\hline & Docentes & 9 & 1,89 & 0,782 & \\
\hline \multirow{2}{*}{ Q3 } & Alunos & 35 & 1,34 & 0,873 & \multirow{2}{*}{0,088} \\
\hline & Docentes & 9 & 1,89 & 0,928 & \\
\hline \multirow{2}{*}{ Q4 } & Alunos & 35 & 1,97 & 0,857 & \multirow{2}{*}{0,686} \\
\hline & Docentes & 9 & 1,89 & 0,782 & \\
\hline \multirow{2}{*}{ Q5 } & Alunos & 35 & 1,43 & 0,739 & \multirow{2}{*}{0,213} \\
\hline & Docentes & 9 & 1,78 & 0,972 & \\
\hline \multirow{2}{*}{ Q6 } & Alunos & 35 & 1,26 & 0,657 & \multirow{2}{*}{0,045} \\
\hline & Docentes & 9 & 0,78 & 1,093 & \\
\hline \multirow{2}{*}{ Q7 } & Alunos & 35 & 1,97 & 0,618 & \multirow{2}{*}{0,001} \\
\hline & Docentes & 9 & 1,00 & 0,866 & \\
\hline \multirow{2}{*}{ Q8 } & Alunos & 35 & 1,94 & 0,765 & \multirow{2}{*}{0,085} \\
\hline & Docentes & 9 & 2,33 & 1,323 & \\
\hline \multirow{2}{*}{ Q9 } & Alunos & 35 & 1,89 & 0,758 & \multirow{2}{*}{0,099} \\
\hline & Docentes & 9 & 2,33 & 0,500 & \\
\hline \multirow{2}{*}{ Q10 } & Alunos & 35 & 1,34 & 0,725 & \multirow{2}{*}{0,098} \\
\hline & Docentes & 9 & 0,89 & 1,054 & \\
\hline \multirow{2}{*}{ Média } & Alunos & & 1,64 & & \\
\hline & Docentes & & 1,71 & & \\
\hline
\end{tabular}

${ }^{(1)}$ Através do teste de Mann-Whitney.

tes. Se alunos revelaram que recebem pacientes com necessidades incompatíveis com seu nível de formação, docentes confirmaram essa questão ao afirmarem que nunca ou algumas vezes participam dessa seleção $(77, \%)$. Por fim a questão 7 suscita uma falha recorrente no ensino da instituição, na qual docentes de uma disciplina desconhecem o que é ensinado nas demais disciplinas, e cuja associação foi a mais significativa nessa comparação de médias. Isso revela uma falta de integração horizontal do curso, uma vez que entre os docentes essa falha foi de $88,9 \%$ ao se combinarem as respostas NUNCA e ALGUMAS VEZES, mas entre os alunos a cobrança desses conhecimentos prévios mostrou um resultado contraditório, posto que $40,0 \%$ é o percentual médio de combinação das respostas MUITAS VEZES e SEMPRE entre os alunos das CAB I. Ou seja, apesar do professor não ter conhecimento do que foi ministrado nas unidades prévias, o aluno registrou a cobrança desse conhecimento que pode ocorrer por simples intuição da parte do docente. Raciocínio idêntico foi aplicado na compa-
Tabela 3 - Teste de Médias entre alunos e docentes da CAB II.

\begin{tabular}{|c|c|c|c|c|c|}
\hline Questão & Grupo & $\mathbf{N}$ & Média & $\begin{array}{l}\text { Desvio } \\
\text { padrão }\end{array}$ & $\begin{array}{c}\text { Valor de } \\
\mathbf{p}^{(1)}\end{array}$ \\
\hline \multirow{2}{*}{ Q1 } & Alunos & 35 & 2,17 & 0,707 & \multirow{2}{*}{0,536} \\
\hline & Docentes & 9 & 2,33 & 0,707 & \\
\hline \multirow{2}{*}{ Q2 } & Alunos & 35 & 1,83 & 0,747 & \multirow{2}{*}{0,826} \\
\hline & Docentes & 9 & 1,89 & 0,782 & \\
\hline \multirow{2}{*}{ Q3 } & Alunos & 35 & 1,6 & 0,651 & \multirow{2}{*}{0,198} \\
\hline & Docentes & 9 & 1,89 & 0,928 & \\
\hline \multirow{2}{*}{ Q4 } & Alunos & 35 & 1,97 & 0,747 & \multirow{2}{*}{0,766} \\
\hline & Docentes & 9 & 1,89 & 0,782 & \\
\hline \multirow{2}{*}{ Q5 } & Alunos & 35 & 1,34 & 0,639 & \multirow{2}{*}{0,121} \\
\hline & Docentes & 9 & 1,78 & 0,972 & \\
\hline \multirow{2}{*}{ Q6 } & Alunos & 35 & 1,89 & 0,758 & \multirow{2}{*}{0,004} \\
\hline & Docentes & 9 & 0,78 & 1,093 & \\
\hline \multirow{2}{*}{ Q7 } & Alunos & 35 & 2,17 & 0,707 & \multirow{2}{*}{0,001} \\
\hline & Docentes & 9 & 1,00 & 0,866 & \\
\hline \multirow{2}{*}{ Q8 } & Alunos & 35 & 1,86 & 0,733 & \multirow{2}{*}{0,053} \\
\hline & Docentes & 9 & 2,33 & 1,323 & \\
\hline \multirow{2}{*}{ Q9 } & Alunos & 35 & 1,51 & 0,612 & \multirow{2}{*}{0,001} \\
\hline & Docentes & 9 & 2,33 & 0,5 & \\
\hline \multirow{2}{*}{ Q10 } & Alunos & 35 & 1,31 & 0,832 & \multirow{2}{*}{0,137} \\
\hline & Docentes & 9 & 0,89 & 1,054 & \\
\hline
\end{tabular}

(1)Através do teste de Mann-Whitney.

ração de médias entre docentes e alunos da CAB II (Tabela 3).

Aqui a significância da associação se deu nas questões 6,7 e 9. A exemplo da CAB I as questões 6 e 7 foram recorrentes, o que significa dizer que persiste entre os alunos e docentes as dificuldades relativas à seleção de pacientes e o os conhecimentos ministrados nas unidades prévias. Nessa comparação surgiu um dado novo, qual seja a significância estatística entre as médias da questão 9 que se refere à participação docente na elaboração do plano de tratamento articulando especialidades e especialistas dentro da visão holística que deve ter o processo. Se 50,0\% dos docentes afirmaram que MUITAS VEZES ou SEMPRE participam efetivamente dessa situação de ensino, apenas 22,9\% dos alunos da CAB II reconheceram essa participação, indicando um aspecto contraditório nas respostas. Na tentativa de saber se havia associação entre a resposta dos alunos com gênero e idade e a resposta dos docentes com gênero e titulação, procedeu-se a análise estatística utilizando o teste do Qui-Quadrado de Pearson e somente uma associação mostrou-se significativa, entre a Q3 - Minha orienta- 
ção ao aluno é de que a sua prática seja realizada de forma integrada e contínua com as demais instâncias do sistema de saúde, sendo capaz de pensar criticamente, de analisar os problemas da sociedade e de procurar soluções para os mesmos - e a titulação docente com $\mathrm{p}=0,045$. Todas as demais associações não foram significativas, com $\mathrm{p}>0,050$.

$\mathrm{Na}$ abordagem qualitativa a análise de conteúdo das respostas à $1^{a}$ questão (Em sua opinião, qual a importância da Clínica de Atenção Básica na formação do futuro cirurgião-dentista, considerando que ela é a primeira experiência clinica do estudante?) permitiu identificar, no discurso discente, cinco categorias temáticas:

a) visão holística do paciente na profissão $(28,6 \%)$;

b) desenvolvimento de habilidades clínicas $(20,0 \%)$;

c) aprender a lidar com pacientes $(17,1 \%)$;

d) atendimento integrado $(17,1 \%)$; e

e) preparo para o SUS $(8,6 \%)$.

Entre os docentes, para essa mesma questão, foram identificadas as categorias:

a) prática clínica integrada $(44,4 \%)$;

b) visão holística $(33,3 \%)$;

c) primeiro contato com o paciente $(33,3 \%)$; $\mathrm{e}$

d) adquirir prática clínica $(22,2 \%)$.

Comparando-se essas duas últimas categorizações é possível observar que há uma convergência de conteúdos entre as respostas dos alunos e dos docentes. Ambos pensam de forma semelhante no que diz respeito à importância da Clínica de Atenção Básica, diferindo apenas na hierarquização dessa importância, pois enquanto os docentes preocupam-se com o treinamento do aluno numa prática clínica integrada, os alunos consideram que a visão holística do paciente na profissão a primeira grande lição da CAB. Essa convergência indica que o pressuposto ideológico contido no PPP da instituição tem alguma ressonância na prática clínica, posto que ao discorrer sobre as competências gerais, está referido, com base nas DCNO, que o esforço pedagógico da instituição deve

\footnotetext{
(...) Concorrer para formação de um cirurgiãodentista generalista, com capacidade e habilidade para examinar o paciente dentro de uma concepção holística e planejar tratamentos baseados em evidências cientificas.
}

A visão do aluno aponta para a importância da $\mathrm{CAB}$ na formação, desocultando claramente a importância do conhecimento sobre o SUS como orientador dessa formação. Contudo, surge uma dúvida: os docentes estão conscientes dessa orientação? Outro aspecto singular é sobre a importância da integração tanto no plano horizontal (as disciplinas/especialidades) quanto no plano vertical (complexidade dos conteúdos). Aqui chama a atenção a importância que se deve a transversalidade de certos conteúdos como relações humanas no trabalho, ergonomia, princípios da administração aplicados à Odontologia, filosofia de trabalho, etc., conteúdos este ministrados no $3^{\circ}$ período, mas que parecem não ser do conhecimento dos docentes das CABs. A análise de conteúdo das respostas à $2^{\mathrm{a}}$ questão ( $A$ CAB está estruturada para o atendimento das necessidades dos alunos e dos pacientes? Justifique sua resposta) indicou dois tipos de análise. A primeira, quantitativa, em que a resposta não obteve 91,6\% de respostas tanto na CABI quando na CAB II entre os alunos e 98,9\% entre os docentes. A segunda quando o discurso revela que a triagem deficiente está presente em $20,9 \%$ das falas dos alunos, seguida de falta de compromisso de alguns professores $(15,2 \%)$, planejamento deficiente com $13.3 \%$ e falta de interdisciplinaridade $(10,5 \%)$ as cinco falas que se destacaram num conjunto de doze razões que justificaram a resposta não a pergunta formulada. Entre os docentes as razões mais fortes foram falha na triagem, espaço reduzido e falta de assiduidade de alguns professores, todas com $20 \%$ de ocorrência. Um olhar atento às respostas permitiu observar que há defeitos de gerenciamento, falta de planejamento, baixa motivação docente, falta de integração, inobservância de princípios fundamentais, entre outras observações. As respostas de alunos e professores revelam um quadro de angústia, mas entre os alunos e um único docente há um sinal de esperança. Imaginamos ser desanimador a consciência crítica de que o processo está errado e não vislumbrar nenhuma saída de curto prazo. A análise de conteúdo das respostas à $3^{\text {a }}$ questão (Que sugestões você oferece para a melhoria da Clínica de Atenção Básica como parte integrante da formação do futuro cirurgião-dentista?) permitiu identificar que para os alunos, num conjunto de dezesseis sugestões, as maiores necessidades de correção devem se dar na correta triagem dos pacientes que devem ter necessidades compatíveis com o nível de formação; na melhoria do planejamento das atividades por parte dos professores; capacitação docente para exercício da interdisciplinaridade; maior empenho, dedicação, envolvimento e dedicação de alguns professores; melhoria do espaço físico da clínica. Entre os docentes as sugestões de melhoria puderam ser agrupadas em três categorias básicas: 
- fortalecimento da interdisciplinaridade;

- organização dos prontuários;

- melhoria na triagem e no espaço físico.

O conjunto dessa respostas revela que se do lado do aluno o apelo é quase desesperador em relação ao compromisso docente que vai desde a compreensão dos objetivos da CAB, passando pelo PPP da FOP, insistindo na assiduidade e na competência para formar, do lado docente há reconhecimento da falta desse conhecimento sobre o PPP, a negligência no cumprimento da ação integrada, o abandono de valores fundamentais como compromisso, assiduidade e competência pedagógica. O docente que apela para o retorno à velha formatação das clínicas estanques seguramente não está atualizado suficientemente em relação às DCNO e parece fazer coro com a afirmação de Marsiglia (1995) quando aquele autor alertava para o modelo de prática baseado na concepção mecanicista da Odontologia com uma forte tendência à especialização precoce por parte do aluno. Os achados de nosso estudo reclamam por uma melhoria didática e pedagógica dos docentes, ${ }^{8}$ e a formação do aluno deve contemplar suas dimensões cognitivas, psicomotoras e afetivas, de modo a prepará-lo para atuar de forma tecnicamente perfeita, eticamente aceitável, socialmente justa e reveladora de cidadania. ${ }^{9}$ Mesmo que atenção ao paciente seja individualizada, ainda assim deve haver uma preocupação com as ações coletivas que podem ser realizadas no âmbito da CAB. Uma não exclui a outra, pelo contrário, reforçam-se mutuamente. O que parece de fato estar acontecendo é que a formação se dá de forma individualista, excessivamente técnica e com dominância da especialização de forma antagônica ao que preconizam as DCNO. ${ }^{10}$ A postura docente deve ultrapassar o estreito limite da técnica e desaguar numa formação que priorize a cidadania, revalorize conceitos ético-morais e dê ao aluno a autonomia e a confiança suficientes para produção e ressiginificação de conhecimentos. Os alunos, de certa forma, reclamam por isso, pois talvez percebam que as técnicas ensinadas hoje logo estarão em desuso, e, mais importante do que conhecê-las e sabê-las executar com grande precisão, é criar hábitos e métodos que valorizem o auto-aprendizado, a abordagem, crítica dos conhecimentos e a permanente inquietação. ${ }^{11}$ A partir da recategorização do conteúdo das respostas de alunos e professores foi possível indicar os eixos condutores das intervenções a serem procedidas na melhoria da $\mathrm{CAB}$, a saber:
1) compreensão e atuação na estratégia de atenção á saúde;

2) fortalecimento da interdisciplinaridade na toma da decisão;

3) requalificação da infraestrutura;

4) compreensão da ideologia de formação baseada no SUS; e

5) compromisso docente com a formação dos alunos.

\section{CONCLUSÕES}

Com base na metodologia utilizada e para esse grupo amostral, parece-nos lícito concluir que não há coerência plena entre o discurso contido nos referenciais teóricos do currículo da FOP e a realidade prática das CABs I e II; a melhoria na triagem, a interdisciplinaridade e o compromisso e competência docente são as melhorias mais exigidas pelos alunos; e o fortalecimento da interdisciplinaridade e a organização dos prontuários são as melhorias mais exigidas pelos docentes.

\section{ABSTRACT}

Primary care clinic: from theoretical discourse to practice reality

Objective: To analyze the ideological coherence of training in order to determine if the practical reality of undergraduate student training at the primary care clinic (PCC) corresponds to the theoretical discourse of the political-pedagogical project of the course. Methodology: exploratory, descriptive, cross-sectional, quantitative and qualitative study, conducted with 35 students and 9 teachers from Primary Care Clinic I and II of the School of Dentistry of Pernambuco. The quantitative study used a questionnaire with ten teaching/learning situations. The answers were rated according to the Likert scale of four options. The qualitative study used the Bardin technique of content analysis on three open questions. Pearson's chisquare test was used to perform the descriptive and inferential statistics, and the Mann Whitney test was used to compare means. Results: The mean comparison test between students and teachers of PCC I was significant only in interdisciplinary, multidisciplinary and transdisciplinary $(p=0.012)$ situations, in selecting patients $(p=0.045)$, and in testing the knowledge and skills acquired in the earlier units $(p=0.001)$. The significant association at PCC II was in selecting patients $(p=0.004)$, in testing the knowledge acquired in previous units $(\mathrm{p}=0.001)$, and in diagnosisrelated support activities $(p=0.001)$. Conclusions: There is no consistency between the discourse of the 
political-pedagogical project of the institution and the practice reality of PCC I and II. Improvements in screening, interdisciplinary studies, teacher commitment and competence, are what is most requested by students, whereas the strengthening of interdisciplinary studies and the organization of records are the improvements most requested by teachers.

\section{DESCRIPTORS}

Dental education. Primary health care. Oral health.

\section{REFERÊNCIAS}

1. Brasil Ministério da Educação e Cultura. Conselho Nacional de Educação. Resolução CNE/CES nº 3/ 2002. Institui as diretrizes curriculares nacionais do curso de graduação em Odontologia. Diário Oficial da União, Brasília, DF, 4 mar. 2002. Seção 1, p. 10.

2. Feuerwerker L, Almeida M Diretrizes Curriculares e projetos pedagógicos: é tempo de ação. Rev. ABENO.2004; 4(1):14-16.

3. FOP Projeto Político-Pedagógico da Faculdade de Odontologia de Pernambuco da Universidade de Pernambuco. Camaragibe, 2007, impresso, $126 \mathrm{p}$.

4. Declaração de Alma-Ata Conferencia Internacional sobre Cuidados Primários de Saúde. Alma-Ata, URSS, 6 a 12 de setembro de 1978. Disponível em: http://www.opas.org.br/promocao/ uploadArq/Alma-Ata.pdf Acesso: 12/03/2010
5. Sácristan JG O currículo: uma reflexão sobre a prática. Trad. Ernani F. da F. Rosa. 3.ed. Porto Alegre: Art Med, 1998. p.37

6. Szymanski H (Organizadora); Almeida LR, Prandini RCAR A entrevista na pesquisa em educação: a prática reflexiva. Brasília: Liber Editora, 2002. 87 p.

7. Minayo MCS O desafio do conhecimento. Pesquisa qualitativa em saúde. São Paulo: Hucitec, Abrasco, 6 ed.,1999, 269 p.

8. Carvalho D, Carvalho ACP, Sampaio H Motivações e expectativas para o curso e para o exercício da odontologia. Rev Ass Paul Cirurg Dent. 1997; 51 (4):345-49.

9. Masetto MT Processo de aprendizagem no ensino superior e suas conseqüências para a docência universitária. In: reunião da associação brasileira de ensino odontológico, 33.; Encontro nacional de dirigentes das faculdades de odontologia, 24., 1998, Fortaleza. Anais... Fortaleza, 1998. p. 9-16.

10. Costa ICC, Unfer B, Oliveira AGRC, Arcieri RM, Saliba NA, Moimaz SAS Integração Universidade-Comunidade: análise das atividades extramurais em Odontologia nas universidades brasileiras. Revista do CROMG, Belo Horizonte, MG, 2000: 6(3):146-153.

11. Pizzatto E, Garbin CAS, Garbin AJ I, Saliba NA O papel do professor no ensino odontológico. Saúde em Debate, Rio de Janeiro, 2004: 28(66):52-57.
Recebido em 14/10/2010

Aceito em 17/12/2010 